\title{
PHYSICAL AND TECHNICAL TRAINING IN FIREFIGHTER'S LADDER COMPETITION
}

\author{
Ioan Sabin SOPA \\ "Lucian Blaga" University, Sibiu, Romania \\ sopa_sabin@yahoo.com \\ Marcel POMOHACI \\ "Lucian Blaga" University, Sibiu, Romania \\ marcelpomohaci@yahoo.com
}

\begin{abstract}
Nowadays, firefighting is becoming more and more demanding with a lot of natural disasters and disasters caused by men, the firefighters must be very well prepared for rapid and efficient intervention, physical training has become one of the key skills that an emergency intervention employee must have. Our research paper is focused on the athletic preparation of firefighting in the ladder climbing competition. The research experimental group was formed by 10 males with age of $30 \pm 3.5$ years old with experience in this kind of competitions between 2 and 7 years. We highlighted the intervention plan and training and their effects on the results of our athletes and also analyze the efficiency of developing motor qualities such as strength, speed, resistance, and coordination. The results show relatively good improvements in the performance time at all 10 athletes and also in the motor qualities level. Conclusions of our research present the efficiency of training athletic skills and also the motor qualities in obtaining better results at the ladder climbing competition.
\end{abstract}

KEYWORDS: psychomotor testing, physical training, firefighter's competitions, ladder competition

\section{Introduction}

Firefighting involves a unique set of stressors, performing a strenuous muscular work; they must climb stairs and ladders, carry and use heavy tools, often above their head or in awkward positions, and they may be called upon to perform difficult rescue operations (Smith, 2011). Current standards recommend that firefighters participate in a fitness program (IAFF, 2007; NFPA, 2008), but it is the responsibility of each individual department to determine whether to institute a fitness program. Like athletes, firefighters experience a dynamic range of performance demands on a daily basis. In the sport arena, sport psychologists have utilized models such as Bronfenbrenner's Ecological Model (Gilbert, 2011; Meyer \& Fletcher, 2009) to conceptualize the multiple performance demands of athletes (i.e., technical, physical, psychological). Similar to the evidence from the sport performance literature, studies examining the physical demands of firefighting have shown that aerobic fitness may be an important aspect of performance among that population as well (Elsner \& Kolkhorst, 2008; Perroni et al., 2010; Sheaff et al., 2010; Williams-Bell et al., 2009). 
Measures of muscular strength and endurance have been linked to performance across sport (Girard \& Millet, 2009) and firefighting alike (Harvey et al., 2008; Michaelides et al., 2008; Rhea et al., 2004; Sheaff et al., 2010; Sothmann et al., 2004). Given the importance of fitness for firefighters, innovative techniques for improving their overall fitness responsive to the unique training needs, culture, and environment of the fire service are needed (Jahnke, 2015).

\section{Objectives of the Research}

The objectives of our research were to present the ladder climbing competition specific to the firefighter's contests and to analyze the methods of physical preparation in order to improve the physical resistance through athletic exercises.

\section{Research Method}

Contests for professional emergency services in Romania are organized annually, by stages, by county/Bucharest emergency inspectorates, under the coordination of the General Inspectorate for Emergency Situations.

The competition tests are the same as those of international firefighters competitions organized by the International Committee for Fire Prevention and Extinction (CTIF).

The contest tests and the number of competitors at each test are:

- ladder climbing competition 8 competitors,

- obstacle run on 100 meters 8 competitors,

- relay race $4 \times 100$ meters 2 teams with 4 competitors,

- realizing the motor pump intervention device

7 competitors.

\subsection{The Ladder Climbing \\ Competition}

There are eight athletes from the lot, who are entitled to two attempts each.

Athletes are equipped with sports gear, helmet, girdle, sports shoes and a "climbing ladder" (Figure no. 1).

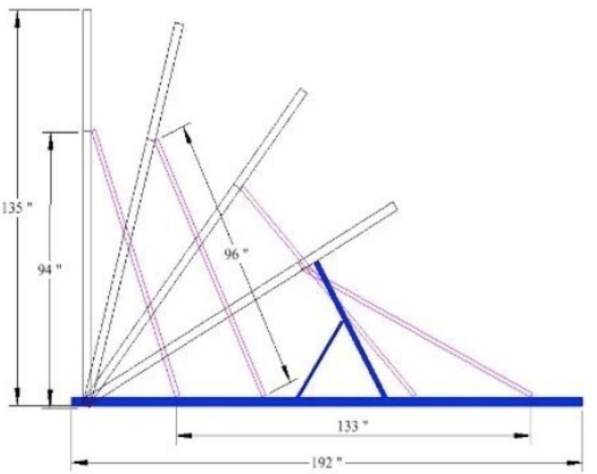

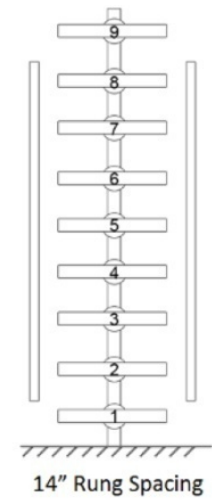

Figure no. 1: Climbing ladder

(Simeonov et al., 2020)

The test runs from the starting line up to the third-floor platform of the competition tower, on two or four parallel competition lines. The tower has a height of 13.12 meters and is constructed with three floors, each of which has openings for windows. Each window has a 40-centimeter width, which rises 3 centimeters above the surface of the frontage (see Figure no. 2). At the "START!" signal, after raising the ladder from the ground, the competitor starts running, carrying it with one or both arms. Before reaching the tower, he raises the ladder over the head, attaches it with the 
hook to the first-floor window sill and starts climbing as conveniently as possible. Levels two and three are climbed in a similar procedure, with the competitor being required to climb the ladder, except for the third-floor window that is crossed and then the athlete is landing with both feet on the platform.

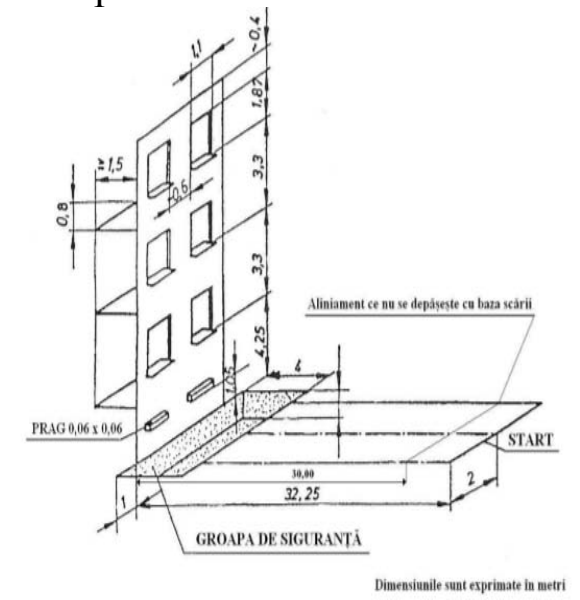

Figure no. 2: Instruction tower

(Simeonov et al., 2020)

\subsection{Research Hypothesis}

If the training and improvement of the motor qualities proposed in this paper were promoted and developed in a scientific, attractive, innovative and professional way by coaches/trainers, ensuring progress in the development of the athletes in the lot, then we would ensure an exponential increase in the performances of each individual athlete, as well as the improvement of the results of professional competitions for emergencies from year to year.

\subsection{Research Place and Sample.} Period and Location of the Research

We conducted the research between March 2018 and September 2018 that is when the ISU Sibiu sports team was selected, continuing with the preparation of professional service competitions in all four stages:

- The first stage - on detachments, which was organized between $1^{\text {st }}$ and $20^{\text {th }}$ of June with larger teams, from the flocks of each subunit.
- The second stage - contest on the county Inspectorate of Sibiu, organized between 20-30 June, with the participation of a lot from each subunit/intervention group, in Sibiu.

- The third stage - contests on the area of the Professional Emergency Services in the region, organized by Emergency Situations Inspectorate "Cpt. Dumitru Croitoru" of Sibiu (ESI) Sibiu during 27-29 July, competition attended by the representative teams of the Emergency Situations Inspectorates Braşov, Covasna, Harghita, Mureş and Sibiu.

- The fourth stage - the final contest, organized between August 23-25, by General Inspectorate for Emergency Situations (GIES) and the Inspectorate for Emergency Situations of Iasi County, at this stage attending the best 12 sports teams of the Romanian Emergency Situations Inspectorates.

As the location of the research, we stated that in principle the study was conducted on the sports ground of the "Firefighter" training base belonging to ESI Sibiu and continued in all the other locations where we held the specific competitions for the emergency services, presented in the paper.

\subsection{Subjects of the Research}

The research subjects were selected among the ESI Sibiu team and was composed of 10 males with age between 27-33 years old (with an average of $30.2 \pm 3.5$ years old) and an experience in the specific contest between 2-7 years old. 


\section{Designing the Training Process}

Table no. 1

The design of the training process

\begin{tabular}{|c|l|c|c|c|c|}
\hline \multirow{2}{*}{ No. } & \multirow{2}{*}{$\begin{array}{c}\text { Methods and instruments of } \\
\text { training }\end{array}$} & \multicolumn{4}{|c|}{ The training micro cycles } \\
\cline { 3 - 6 } & \multicolumn{2}{|c|}{$\begin{array}{c}\text { Tllocated } \\
\text { percentage }\end{array}$} & Time & $\begin{array}{c}\text { Allocated } \\
\text { percentage }\end{array}$ & Time \\
\hline 1 & $\begin{array}{l}\text { Exercises specific to the athletic } \\
\text { events }\end{array}$ & $33.3 \%$ & 120 minutes & $27.78 \%$ & 100 minutes \\
\hline 2 & $\begin{array}{l}\text { Exercises for developing the } \\
\text { motor qualities }\end{array}$ & $16.67 \%$ & 60 minutes & $11.11 \%$ & 40 minutes \\
\hline 3 & $\begin{array}{l}\text { Execution on segments of the } \\
\text { specific race obstacles }\end{array}$ & $16.67 \%$ & 60 minutes & $11.11 \%$ & 40 minutes \\
\hline 4 & $\begin{array}{l}\text { Global execution of the race } \\
\text { with obstacles }\end{array}$ & $33.3 \%$ & 120 minutes & $50 \%$ & 180 minutes \\
\hline
\end{tabular}

Note: The training time is 6 hours a day, totaling 360 minutes.

The following methods were used to correct mistakes and performance difficulties by processing the information provided by video analytics:

- Variation of external conditions.
- The combination of some (automated) skills already learned.

- Exercising with time control.

- With variation of information.

- Exercises for imitation of imposed motor sequences.

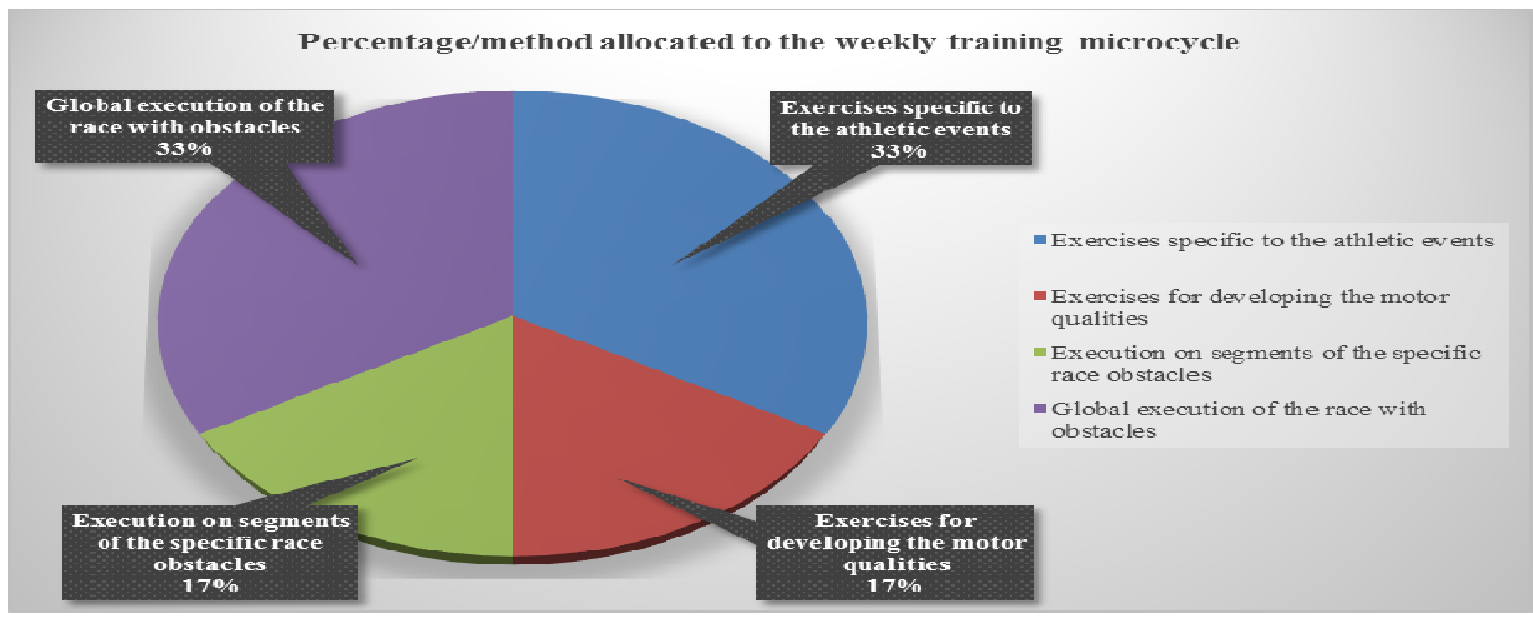

Figure no. 3: Percentage/Method assigned to the weekly training microcycle

Within the motor training program, it was found that motion coaching exercises are done separately and are specific.

Specific training

- exercises from the basic technique of the event;

- technical analytical means;

- moving techniques under heavy conditions (over obstacles, with dumbbells in hands);
- technique means against time;

- combined technical means in applicative relays;

- measuring techniques performed in endurance conditions;

- development of speed in various conditions (starts from different positions, performing motor actions in a delimited space, performing tasks against time, etc.). 
As a result of the preliminary research we present the technical development of some training programs called microcycles of training composed of the weekly microcycle and the precompetitive microcycle based on the "time and percentage allocated" conditions in the execution to the optimal, biomechanically inspired by the models of the specialized literature (Dragnea, 2000).
Within the weekly microcycle, the highest share of time is allocated to exercises specific to athletic tests (120 minutes), exercises for the development of motor skills (60 minutes) and segments of the specific events (60 minutes), for a total of 240 minutes from a total of 360 minutes of daily workouts. In percent, this time represents $66.67 \%$ of the training time.

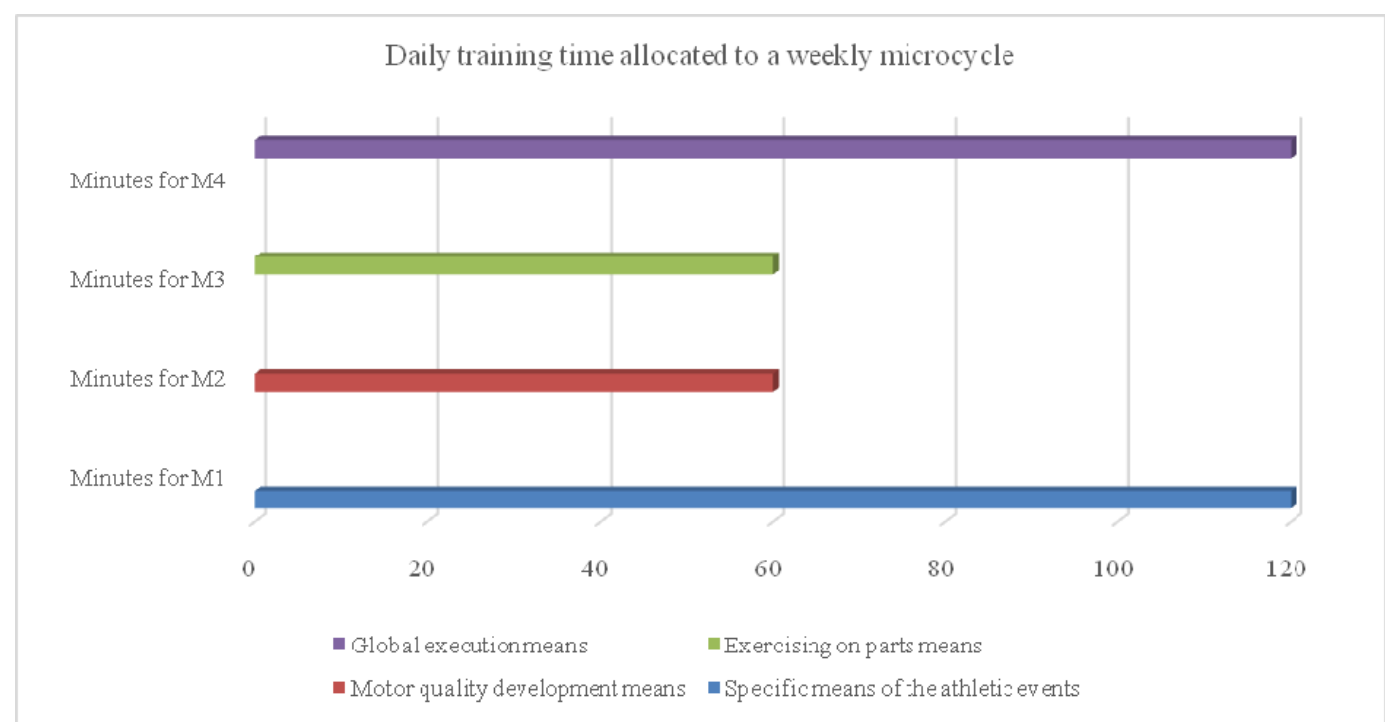

Figure no. 4: Daily training allocated to a weekly microcycle

In the precompetitive microcycle, the allocation of time rules changes as follows: exercises specific to athletic tests (120 minutes), exercises for the development of motor skills (30 minutes) and the execution of specific parts of the event (30 minutes), summing a total of 180 minutes, from a total of 360 minutes.

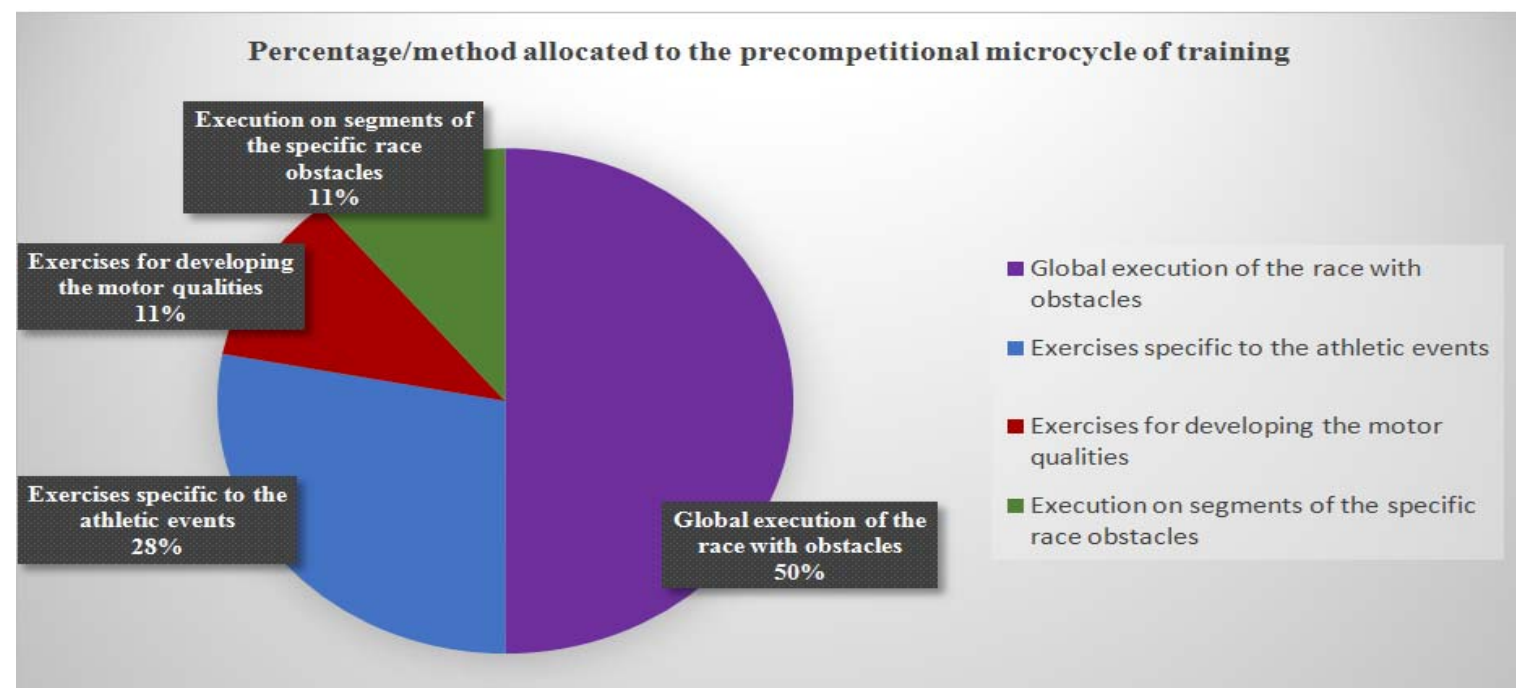

Figure no. 5: Percentage/method allocated to the pre competition microcycle of training 
Exercises for the general execution of the events specific to structures for emergency situations are allocated to 180 minutes, ie $50 \%$ of the time limit. Overall, analyzing the two types of training, one can conclude that the exercises and means specific to athletics have been granted an increased time. These training methods have been established by us as an experiment to verify the effectiveness of the training and its results reflected in the individual performances of the subjects selected in the experiment.

\section{Daily training time allocated to the precompetitional microcycle}

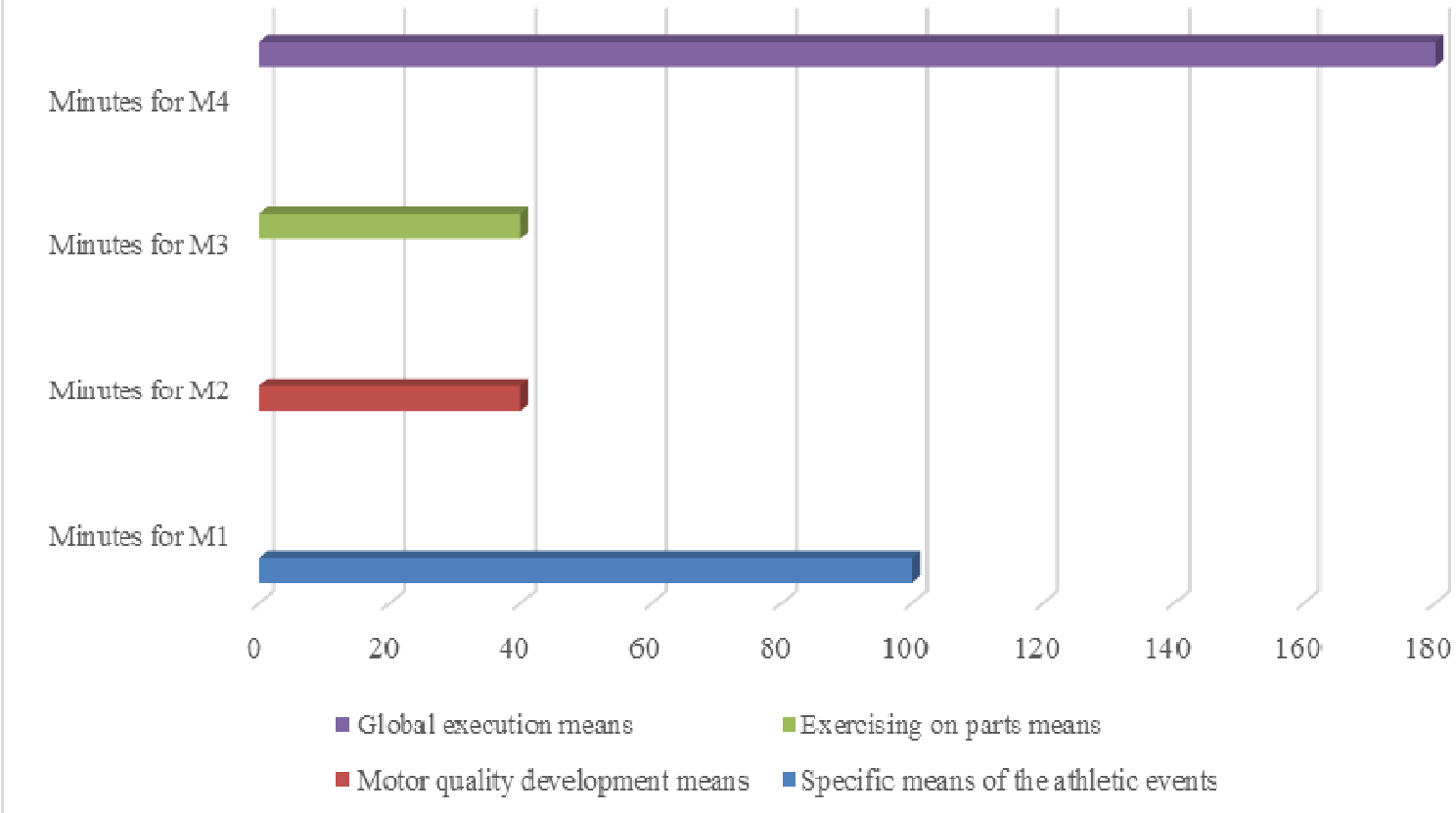

Figure no. 6: Daily training time allocated to the pre competition microcycle

We have found that by kinematic analysis and processing of recorded parameters, due to a motor based program focused on training and athletic exercises, by combining appropriate technical abilities, automated and through repetitions as well as on the coordination training specific to the competitions of the professional services of the emergency situations we can improve the accuracy of execution.

For this reason, we appreciate and propose to create a technical error nomenclature in which to specify the causes of individual technical errors in the athletes in the team, taking into account that it is imperative to lay the foundations of an optimized individualized technique that will lead to a better performance.

\section{Results}

5.1. Execution on Segments and Assembly of the "Ladder Climbing"

a. The technique demonstration of the test, the entire test and on parts with an explanation.

b. Splitting the test on each part separately.

c. The entire execution of the test.

d. Training in the execution of the test.

- Start, $15 \mathrm{~m}$ run, hang the ladder on the first floor and 2 steps on the scale (5 reps).

- $10 \mathrm{~m}$ run and climbing to the first floor from 3 to 3 steps (5 repetitions).

- The indication of the staircase from the first floor to the second floor, 3 times and 2 steps on the scale ( 5 repetitions). 
- $10 \mathrm{~m}$ run, hanging the ladder to the first floor and climbing the window sill (3 repetitions).

- Start with window ladder, $32.25 \mathrm{~m}$ run and hanging on the first floor of the training tower (2 reps).

- Start with window ladder, $32.25 \mathrm{~m}$ run, hanging on the first floor of the tower, climbing the sill window and climbing the ladder by hanging on the second floor sill (2-3 repetitions).

- Start, $32.25 \mathrm{~m}$ run, hang the ladder, climb to the first floor, handle the ladder from the window sill on the first floor and climb to the second floor. Descending the tower stairs and regroup in the team (1-2 reps).

Managing the ladder in three times from the first-floor window to the second floor and picking up the climbing position. Climbing to the second-floor window Barem: Under 7 seconds.

- Start, $32.25 \mathrm{~m}$ run, hang the ladder to the first floor and climb to the first floor, climb on the window sill - Barem: under 12 seconds.
- Start, $32.25 \mathrm{~m}$ run, climb to the first floor, climb on the sill and raising the ladder - Barem: under 15 seconds.

- Training in the execution of the "Ladder climbing" test - in accordance with the standardized scales provided in the order.

The next step in the continuation of this research, according to the content of the experiment, is the analysis of the results obtained from the practical control tests. For this purpose, the tables and charts on the following pages, the tables containing the timings and the marks obtained in the practical examinations of each subject, of each intermediate or final model, were of great help for us. For a better analysis of the data obtained, we tried to present by the graphical method, times achieved and the scores obtained by the group of subjects at the end of each intermediate model and the final one. The record of the results obtained at the "Ladder climbing" control test by the athletes in the team.

Table no. 2

The results of the tests at the ladder climbing

\begin{tabular}{|c|c|c|c|c|c|c|c|c|c|c|c|}
\hline \multirow{2}{*}{ Statistics } & \multirow{2}{*}{ Age } & \multicolumn{10}{|c|}{ The periodicity of the test } \\
\cline { 3 - 14 } & & Initial Test & \multicolumn{2}{|c|}{ Test 1 } & \multicolumn{2}{|c|}{ Test 2 } & \multicolumn{2}{|c|}{ Test 3 } & \multicolumn{2}{c|}{ Final test } \\
\cline { 3 - 13 } & Perf. & Note & Perf. & Note & Perf. & Note & Perf. & Note & Perf. & Note \\
\hline Average & 29.2 & 21.50 & 8.9 & 21.08 & 8.95 & 20.61 & 9.25 & 20.18 & 9.25 & 19.5 & 9.75 \\
\hline Max. val. & 32 & 22 & 10 & 22 & 10 & 22 & 10 & 22 & 10 & 21 & 10 \\
\hline Min. val. & 26 & 17.5 & 8 & 17.3 & 8 & 17 & 8 & 16.3 & 8 & 16.4 & 9 \\
\hline Sta. dev. & 1.72 & 1.25 & 0.70 & 1.37 & 0.72 & 1.33 & 0.68 & 1.71 & 0.93 & 1.19 & 0.34 \\
\hline Variab. & 3.29 & 1.75 & 0.54 & 2.10 & 0.58 & 1.97 & 0.51 & 3.25 & 0.96 & 1.56 & 0.13 \\
\hline Kurtosis & -0.23 & 7.15 & -1.06 & 5.97 & -1.12 & 5.53 & -1.00 & 1.12 & -2.07 & 4.43 & 0.57 \\
\hline Skewness & -0.37 & -2.57 & 0.43 & -2.30 & -0.03 & -2.12 & -0.57 & -0.95 & -0.56 & -1.81 & -1.18 \\
\hline
\end{tabular}

Statistical comparison between the initial testing and the final testing $P$ value and statistical significance: The two-tailed $\mathrm{P}$ value is less than 0.0001 . By conventional criteria, this difference is considered to be extremely statistically significant.

Confidence interval: The mean of Group One minus Group Two equals 1.550

95\% confidence interval of this difference: From 1.104 to 1.996

Intermediate values used in calculations:

$\mathrm{t}=7.8543$

$\mathrm{df}=9$

standard error of difference $=0.197$

Review your data: 


$\begin{array}{ccc}\text { Group } & \text { Group One } & \text { Group Tw } \\ \text { Mean } & 21.050 & 19.500 \\ \text { SD } & 1.322 & 1.251 \\ \text { SEM } & 0.418 & 0.396 \\ \text { N } & 10 & 10\end{array}$

From the tables and graphs made, the progress of the whole experimental group appears quite evident in the present research, with a statistically significant difference between the initial test and the final test. The results obtained from the first practical control tests were weaker because the first intermediate mark was awarded after only two days of training ( 2 exercises), aiming to verify the initial technical-tactical preparation of this group of subjects. There were 4 weeks (18 training sessions) between the first and the second scoring, between the second and the third test, passed 5 weeks (23 training sessions), between the third test and the fourth test passed 5 weeks (20 training sessions) and between the 4th test and the final test passed 4 weeks, respectively 19 training.

From the analysis of the tables and graphs made, it results that during the entire experiment, the experimental group made a uniform progress from one scoring to another, highlighting several significant aspects: there is a steady progress, individually and collectively (shown in tables), of all the subjects that have been the subject of our research, from the initial test to the final test. Following the conclusion of the experiment, we were able to affirm that some of the results obtained by some subjects are not only due to the training process during the training hours but are also a consequence of the regular exercise of the physical exercises and of the movement in general over the training program.

Progress is very obvious in the last graph presented, the dynamics of the progress between the scoring from the initial test compared with the final test score, the average of the experimental group obtained at the first notation being 8,90 and the final mark, the average of 9,75, so a progress of 0.85 points in conditions where all the subjects checked were part of the ESI sports team Sibiu. The most important aspect to note is that the average execution time on the sample dropped from an average of $21.5 \mathrm{sec}$ to an average of $19.5 \mathrm{sec}$ so one second and 55 improvements.

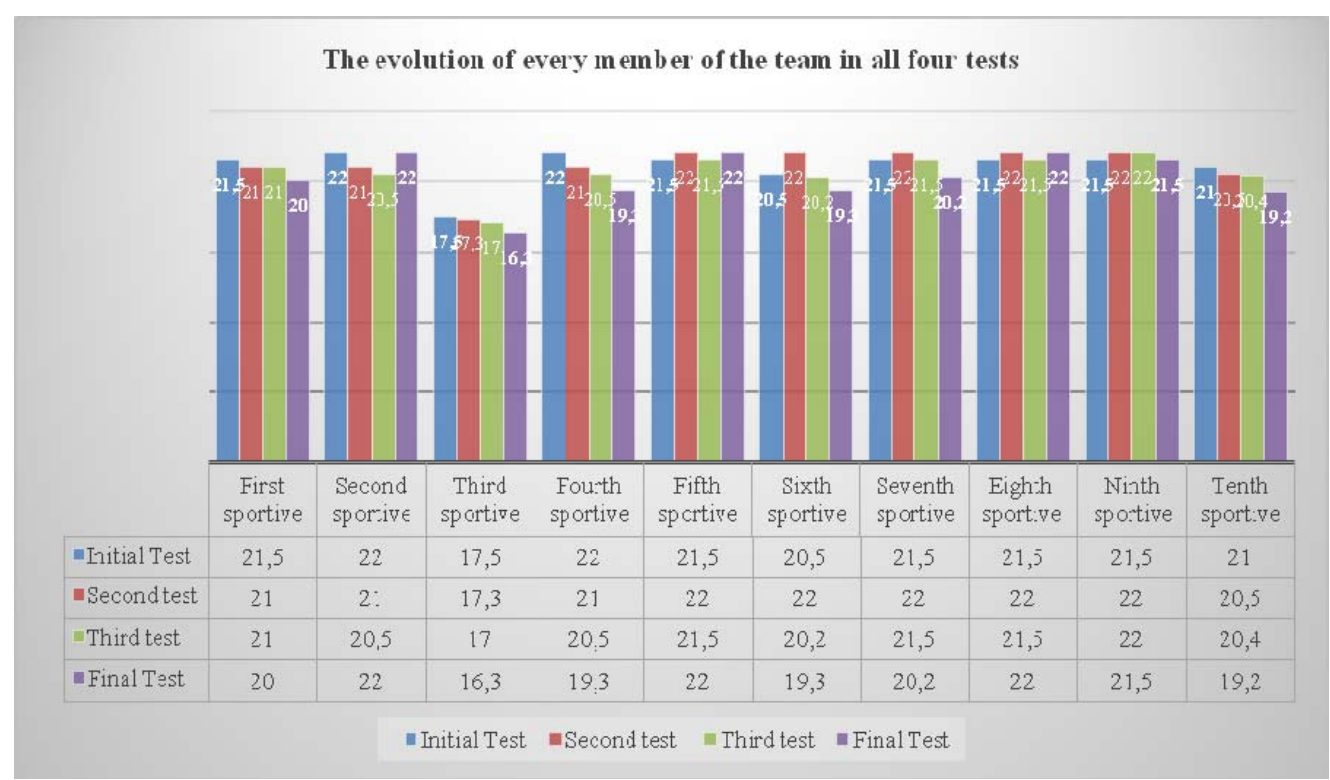

Figure no. 7: The evolution of every member of the team in all four tests 


\section{Discussions}

Practical discipline, with a vocational character, athletics is one of the most important means of physical education and sport. Its valences are formative and competitive, both in practice, at the population level and for those who become athletes of performance. The rationalization and standardization of sports training have been and is a concern of specialists, since sports training has been individualized as a process, being subordinated to sport performance objectives and structured to better utilize the biological and mental potential of the athlete, its level of aspirations. Streamlining and standardizing sports training has always resulted in increased training efficiency, improved time savings, shortening paths to achieving high performance.

The research carried out through a program of recording the main parameters, recorded during the times of the competition tests conducted with the professional emergency services, highlighted the analysis and interpretation of the results, and that the general hypothesis was confirmed. This was accomplished by correcting technical errors and optimizing training with athletic exercises. It was also found that after analyzing the results of the basic research, the assumed working hypotheses were fulfilled, finding improvements in the objectification of the technique of the competition race specific to the professional services for emergency situations, following the statistical mathematical processing confirming the hypothesis of the research.

Based on the results obtained in our experiment, the technical-methodical training sessions are as follows:

- At the end of the research and analysis of the registered parameters, it is ascertained that by applying the training program with athletic exercises the athletes improve their speed of execution, strength, and skill.
- Enhanced coordination and mobility in final testing was found in all subjects;

- The monitoring of the training based on the effort dynamics training programs with specific means of athletics allowed the initial, intermediate and continuous evaluation found in the evidence of the control samples as well as the final evaluation confirmed by the performances of the competitions.

- Analytical use of kinetic parameters through video recording complements and argues scientifically the direct guidance of athletes through individual technical and physical training programs in order to obtain an individual performance of the procedures and technical elements of the competition test specific to the professional services for situations emergency.

- It is necessary to train the staticdynamic analyzer leading to the progress found in the second test.

On the second test, there is an improvement by training the muscular power of the extensor muscles in the lower train.

- The detected automatism can lead to a more efficient performance and value increase.

\section{Conclusions}

In conclusion, there is an obvious unity between the planning of the sports training, the formulation in planning the objectives of strength training, technicaltactical training, psychological training and the preparation of physical form in sport. This mechanism has a periodic and cyclical character resulting from the cyclicality proprieties that influence human evolution. Cyclicality in evolution (evolution stagnation - involution - stagnation evolution, so on) limits the possibilities of 
evolution of the human organism. "Growth is not unlimited and can come into conflict with the functional possibilities of the body and the health of the body" (Dragnea, 2000, p. 24).

Technical and tactical training must be done concurrently with the development of motor skills, as there is very close mutual conditioning between them. Their separate treatment has been found to hamper performance improvements. Physical training is more technically related in some stages than in others. It is not possible to improve the technique of the athletes in the teams of the professional emergency services contests, if there is not a corresponding increase in the level of the physical training, taking into account the general laws of the movement by the morpho-functional particularities of each athlete in part. Trainers and instructors play a key role in maintaining the level of physical education and training, by always using the most appropriate methods and working methods to develop and consolidate skills and abilities. Aspects and data contained in this research, we personally consider that as a result of increasing the requirements and conditions for training and evaluation of the personnel in emergency structures, it is an instructive guide for trainers in the planning and carrying out of specific training sessions and physical training.

Throughout the experiment, we have always watched to apply the results of the study conducted by the instructors or coaches, by choosing the most appropriate training and development methods to achieve the following objectives among the results:

- forming and developing basic physical qualities: strength, force, speed, resistance,

- the transmission of the information necessary for the development of initiative, ingenuity, will, decision, self-confidence, courage, attention, and orientation,

- developing skills to act quickly, accurately and safely, including the physical and mental fatigue.

\section{REFERENCES}

Dragnea, A. (2002). Teoria educației fizice și a sportului. Bucureşti: FEST.

Elsner, K. L., \& Kolkhorst, F. W. (2008). Metabolic demands of simulated firefighting tasks. Ergonomics, Vol. 51, Issue 9, 1418-1425.

Gilbert, J. N. (2011). Teaching sport psychology to high school student-athletes: The Psychological UNIFORM and the Game Plan Format. Journal of Sport Psychology in Action, Vol. 2, Issue 1, 1-9.

Girard, O., \& Millet, G. P. (2009). Physical determinants of tennis performance in competitive teenage players. Journal of Strength \& Conditioning Research, Vol. 23, Issue 6, 1867-1872.

Harvey, D. G., Kraemer, J. L., Sharratt, M. T., \& Hughson, R. L. (2008). Respiratory gas exchange and physiological demands during a fire fighter evaluation circuit in men and women. European Journal of Applied Physiology, Vol. 103, Issue 1, 89-98.

International Association of Fire Fighters/International Association of Fire Chiefs. (2007). The fire service joint labor management wellness/fitness initiative. Washington, DC.

Jahnke, S. A., Hyder, M. L., Haddock, C. K., Jitnarin, N., Day, R. S., \& Poston Walker, S. C. (2015). High-intensity fitness training among a national sample of male career firefighters. Safety and health at work, Vol. 6, 71-74.

Meyer, B. B., \& Fletcher, T. B. (2009). A systems approach to applied sport psychology. Annual meeting of the Association for Applied Sport Psychology, Salt Lake City, Utah. 
Michaelides, M. A., Parpa, K. M., Thompson, J., \& Brown, B. (2008). Predicting performance on a firefighter's ability test from fitness parameters. Research Quarterly for Exercise and Sport, Vol. 79, 468-475.

National Fire Protection Association. (NFPA) 1583. (2008). Standard on health-related fitness programs for Fire Department members. Technical Committee on Fire Service Occupational Safety and Health. Quincy, MA.

Perroni, F., Tessitore, A., Cortis, C., Lupo, C., D'Artibale, E., Cignitti, L., \& Capranica, L. (2010). Energy cost and energy sources during a simulated firefighting activity. Journal of Strength and Conditioning Research, Vol. 24, 3457-3463.

Peterson, M. D., Alvar, B. A., \& Rhea, M. R. (2006). The contribution of maximal force production to explosive movement among young collegiate athletes. Journal of Strength \& Conditioning Research, Vol. 20, Issue 4, 867-873.

Rhea, M. R., Alvar, B. A., \& Gray, R. (2004). Physical fitness and job performance of firefighters. Journal of Strength of Conditioning Research, Vol. 18, Issue 2, 348-352.

Sheaff, A. K., Bennett, A., Hanson, E. D., Kim, Y., Hsu, J., Shim, J. K., Edwards, S. T., \& Hurley, B. F. (2010). Physiological determinants of the candidate physical ability test in firefighters. Journal of Strength and Conditioning Research, Vol. 24, Issue 11, 3112-3122.

Simeonov, P., Hsiao, H., Armstrong, T., Fu, Q., Woolley, C., \& Kau, T. Y. (2020). Effects of aerial ladder rung spacing on firefighter climbing biomechanics. Applied Ergonomics, Vol. 82, https://doi.org/10.1016/j.apergo.2019.102911.

Smith, D. L. (2011). Firefighter fitness: improving performance and preventing injuries and fatalities. Current Sports Medicine Reports, Vol. 10, Issue 3, 167-72.

Sothmann, M. S., Gebhardt, D. L., Baker, T. A., Kastello, G. M., \& Sheppard, V. A. (2004). Performance requirements of physically strenuous occupations: validating minimum standards for muscular strength and endurance. Ergonomics, Vol. 47, Issue 8, 864-875.

Williams-Bell, F. M., Villar, R., Sharratt, M. T., \& Hughson, R. L. (2009). Physiological demands of the firefighter candidate physical ability test. Medicine \& Science in Sports \& Exercise, Vol. 41, 653-662. 